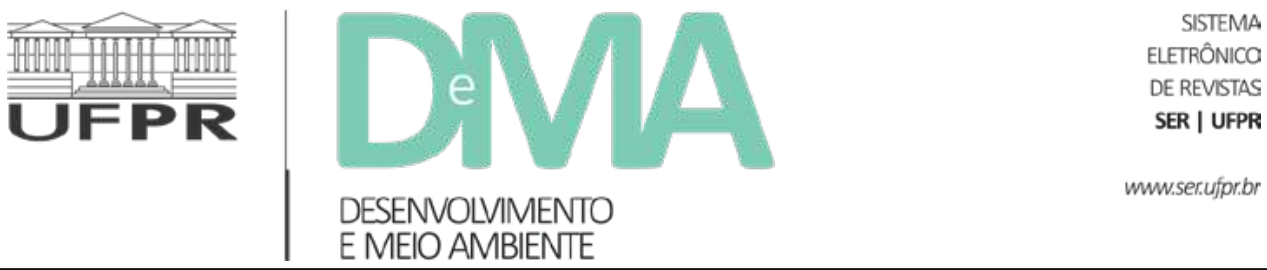

\title{
Desmatamento e incêndios florestais transformando a realidade da Reserva Extrativista Chico Mendes
}

\section{Deforestation and forest fires transforming the reality of the Chico Mendes Extractive Reserve}

\author{
Flúvio de Sousa MASCARENHAS ${ }^{*}$, Irving Foster BROWN², Sonaira Souza da SILVA ${ }^{3}$ \\ ${ }^{1}$ Instituto Chico Mendes de Conservação da Biodiversidade (ICMBio), Rio Branco, AC, Brasil. \\ ${ }^{2}$ Woods Hole Research Center (WHRC), Massachusetts, EUA. \\ ${ }^{3}$ Universidade Federal do Acre (UFAC), Cruzeiro do Sul, AC, Brasil.
}

*E-mail de contato: fluvio.mascarenhas@icmbio.gov.br

Artigo recebido em 9 de abril de 2018, versão final aceita em 15 de outubro de 2018.

RESUMO: $\quad$ A Reserva Extrativista Chico Mendes (RECM) é uma unidade de conservação de uso sustentável que cobre quase um milhão de hectares, localizada no estado do Acre, no sudoeste da Amazônia brasileira. Ela tem 10 mil habitantes estimados. É um exemplo concreto do legado de Chico Mendes e emblemático dos desafios enfrentados pelas unidades de conservação na Amazônia. Mudanças significativas ocorreram desde que a reserva foi criada, em 1990, com relação ao desmatamento e degradação florestal. Cerca de 5,6\% da RECM, 54.741ha, foi desmatado entre 1997 a 2016, segundo dados do Prodes/Inpe. Uma comparação das taxas de desmatamento registradas pelo Prodes e pelo Projeto de Mudança Florestal Global (GFC) mostrou resultados enganosamente semelhantes para o período de 2000 a 2016: 31.485ha e 34.102ha, respectivamente. Somente durante o período de 2007 a 2011, os dois monitoramentos deram resultados semelhantes. De 2012 a 2016, o GFC registrou taxas anuais cerca de 75\% mais altas do que as taxas anuais do Prodes. O tamanho médio dos polígonos por ano aumentou três vezes nos últimos 10 anos, de 3 ha/ano (2001 a 2006) para 8 ha/ano (2007 a 2016), sendo 92\% expansão de desmatamentos existentes. A distribuição espacial do desmatamento concentrou-se em 10 dos 46 seringais da RECM, alguns dos quais registraram mais de 50\% de desmatamento até 2016 segundo o Prodes. Os incêndios florestais têm sido a grande preocupação para a Reserva Extrativista Chico Mendes, devido ao impacto de 50.363ha de florestas degradadas pelo fogo, área igual ao total de desmatamento. Essa degradação afeta o estoque de carbono e danifica as espécies utilizadas no extrativismo. Cicatrizes dos incêndios florestais contíguas > 1.000ha formaram mais da metade da área total queimada e ocorreram em áreas pouco povoadas da RECM. 
Secas severas parecem ser fundamentais para a propagação de incêndios florestais que tiveram origem em queimadas de limpeza e preparo do solo para pastagem e/ou agricultura de menos de 30 ha, propiciando um novo paradigma de degradação florestal pelo fogo. Com o aumento do tamanho médio dos polígonos de desmatamento, a RECM enfrenta uma situação que vai contra o legado de Chico Mendes: a expansão das áreas desmatadas para pastagens e a degradação das florestas em pé, a base para a manutenção do extrativismo, pelo fogo.

Palavras-chave: expansão de pastagens; incêndios florestais; secas; Amazônia; conservação.

ABSTRACT: The Chico Mendes Extractive Reserve (RECM) is a sustainable use conservation unit that covers almost one million hectares, located in the state of Acre, in Brazil's southwestern Amazon. Withten thousand in habitants estimated, it is a concrete example of the legacy of Chico Mendes and an emblematic one of the challenges faced by conservation units in the Amazon. Significant changes occurred since the reserve was created in 1990 in relation to deforestation and forest degradation. About 5.6\% of the RECM, 54,741 ha, was deforested between 1997 and 2016, according to Prodes / Inpe data. A comparison of deforestation rates recorded by Prodes and the Global Forest Change Project (GFC) showed deceptively similar results for the period 2000 to 2016: 31,485ha and 34,102ha, respectively. Only during the period 2007 to 2011, the two monitoring systems gave similar results. From 2012 to 2016, the GFC recorded annual rates about $75 \%$ higher than the annual Prodes rates. The average size of polygons per year increased $3 x$ in the last 10 years, from 3 ha/year (2001 to 2006 ) to 8 ha/year (2007 to 2016), with $92 \%$ expansion of existing deforestation. The spatial distribution of deforestation was concentrated in ten of the 46 RECM rubber plantations, some of which recorded more than $50 \%$ deforestation by 2016, according to Prodes. Forest fires have been a major concern for the Chico Mendes Extractive Reserve, due to the impact of 50,363ha of forests degraded by fire, an area equal to total deforestation. This degradation affects carbon stocks and damages the species used for extractivism. Scars from contiguous forest fires $>1,000$ ha formed more than half of the total burned area and occurred in sparsely populated areas of RECM. Severe droughts appear to be fundamental for the propagation of forest fires that originated in cleaning and tillage fires for pasture and/or agriculture of less than 30ha, providing a new paradigm of forest degradation by fire. With the increase in the average size of deforestation polygons, the RECM faces a situation that goes against the legacy of Chico Mendes: an expansion of deforestation for pastures and fire degradation of the forests that form the base of extractivism.

Keywords: pasture expansion; forest fires; droughts; Amazon; conservation.

\section{Introdução}

Um dos legados mais concretos de Chico Mendes, líder seringueiro, sindicalista e ambientalista brasileiro assassinado em 1988, é a reserva extrativista com o seu nome, Reserva Extrativista Chico Mendes - RECM. Entretanto algumas perguntas ainda são um dilema quando visitamos a RECM: é um sucesso ou um fracasso? Qual o futuro da reserva? Essas perguntas vêm de uma preocupação sobre uma área de quase um milhão de hectares de florestas tropicais úmidas em que habitam cerca de 10 mil pessoas cujas atividades produtivas supostamente não causariam degradação florestal, entretanto com grande pressão antrópica no seu entorno.

Neste texto, examinamos algumas perspectivas para ajudar a encontrar as respostas a essas perguntas, principalmente no contexto biofísico em que elas são feitas. A RECM não existe isolada no tempo ou espaço. Ela cobre terras que pertencem a sete municípios no estado mais ocidental do Brasil, 
no maior bioma contíguo de florestas tropicais no mundo. Nos lados leste e sul, a RECM está rodeada pela BR-317 que faz parte da estrada do Pacífico, estrada Interoceânica binacional que liga o Brasil aos portos do Oceano Pacífico no litoral sul do Peru, que gera mudanças e pressões socioeconômicas (Zambrano et al., 2010). A reserva foi criada antes da Rio-92 e a sua história acompanha o desenvolvimento de políticas públicas globais sobre o meio ambiente, especialmente aquelas ligadas à conservação de florestas tropicais e a mudanças climáticas (Keohane \& Victor, 2016).

Um indicador da dinâmica socioambiental da RECM envolve as mudanças da cobertura florestal nas últimas décadas. Este artigo visa a fornecer informações específicas sobre essas mudanças para ajudar a traçar possíveis cenários futuros. Há 26 anos, Brown et al. (1992) concluíram que os moradores da RECM estavam manejando o desmatamento com pouco impacto. Eles avisaram, porém, que mudanças nas fontes de renda na reserva e o crescimento populacional poderiam modificar esse padrão. Outro objetivo deste artigo é avaliar se o desmatamento manteve o padrão de mais de duas décadas atrás ou se emergiram novos padrões.

\section{Contexto global}

Apesar de um esverdeamento ("greening") da vegetação global (Munier et al. 2018), principalmente associado ao efeito da maior concentração de gás carbônico na atmosfera (Zhu et al., 2016), na Amazônia a taxa do acúmulo de carbono na biomassa da floresta está diminuindo (Brienen et al., 2015).Em outras palavras, as florestas maduras da Amazônia têm absorvido mais carbono do que os países amazônicos têm emitido via queima de combustíveis fósseis (Phillips \& Brienen, 2017), mas esse sumidouro está se reduzindo em magnitude. No mesmo tempo, nos últimos anos cresceu a degradação de florestas na Amazônia, fazendo com que elas se tornem uma fonte de emissão líquida de carbono para a atmosfera (Baccini et al., 2017).

Junto ao esverdeamento da vegetação global, ocorreu uma perda global da cobertura florestal tropical, inclusive na Amazônia, que está afetando o funcionamento de ecossistemas (Ceballos et al., 2017) e a preservação da biodiversidade do planeta (de Oliveira et al., 2018). O prolongamento da estação seca na parte sul da Amazônia (Fu et al., 2013) e modelos de previsão (Gloor et al., 2015) sugerem que o ciclo hidrológico se intensificará, com chuvas mais intensas no período chuvoso e secas mais intensas e prolongadas no período do verão amazônico. Alguns autores apontam que estamos perto de um ponto de mutação ("tipping point") que pode provocar uma mudança no ciclo hidrológico, o que resultaria num colapso da floresta amazônica (Lovejoy \& Nobre, 2018).

Esses fatores e outros, também de âmbito global, afetam a RECM, tanto no que toca ao seu futuro quanto no que se refere a uma avaliação de seu fracasso ou sucesso.

\section{Contexto da Amazônia}

A RECM foi a segunda reserva extrativista criada na Amazônia brasileira e serve como modelo para outras reservas do mesmo tipo. Na RECM, antes da seca de 2005, as florestas estavam ampliando a sua biomassa em cerca de $1,5 \mathrm{mg} \mathrm{ha}^{-1}$ ano $^{-1}$ (faixa de 1 a $2 \mathrm{mg} \mathrm{ha}^{-1}$ ano $^{-1}$, Phillips et al., 2010, Material 
Suplementar), ou usando uma conversão de $0,5 \mathrm{mg}$ $\mathrm{C} / \mathrm{mg}$ biomassa, isto é, equivalente a cerca de 0,8 $\mathrm{mg} \mathrm{C}$ ha $^{-1}$ ano $^{-1}$. Numa área de quase 1 milhão de hectares de floresta, isto significa que o acúmulo de carbono da RECM no período de 1991 a 2005 ficou entre 0,5 e 1 milhão de toneladas de carbono por ano. Esse acúmulo real não foi contabilizado em incentivos e pagamentos de serviços ambientais, como o mecanismo de Redução de Emissões pelo Desmatamento e a Degradação Florestal (REDD+) (Pjillips \& Brienen, 2017). Fatores como a degradação de florestas via atividade madeireira, incêndios florestais (Aragão et al., 2018) e mortalidade acentuada de árvores de grande porte por causa de secas severas (Phillips et al., 2010) ainda não têm entrado na contabilização de REDD, porém têm crescido em importância.

Um indicador-chave de mudança da cobertura florestal tem crescido desde 2012-2013 na Amazônia brasileira e no Acre (Fearnside, 2017; Tyukavina et al., 2017; Inpe, 2018). Existem várias estimativas das taxas de desmatamento que tanto ajudam quanto complicam as análises. Ter mais de uma estimativa fornece confiança quando elas são consistentes entre si, mas quando elas divergem geram interpretações possivelmente equivocadas. Neste artigo analisamos duas estimativas para a RECM: a do Prodes-Inpe (2018) e a do Projeto de Mudança da Floresta Global (GFC), de Hansen $e t$ al. (2013).

Em 2005, uma seca severa teve o seu epicentro no Acre e propiciou incêndios florestais em mais de 300.000 ha de florestas maduras, incluindo as da RECM (Brown et al., 2006; Brown et al., 2011). As secas em 2010 e 2016 geraram a preocupação de que secas severas ocorrem com mais frequência e afetam as florestas do Acre, propiciando incêndios florestais (Silva et al., 2018).

Desde 2005, o leste do Acre tem sido palco de eventos climáticos extremos, com inundações frequentes de cidades, incêndios florestais e secas severas em escalas de tempo de um a cada seis anos, consistentes com o que ocorre em outras partes da Amazônia (Marengo \& Espinoza, 2016). Esses fatores biofísicos já estão afetando a vida dos moradores da RECM. Durante a seca de 2016, Francisco de Araújo, uma das lideranças na RECM, divulgou via mídia social a sua preocupação com o potencial de incêndios florestais nas florestas da $\mathrm{RECM}^{1}$. A seca extrema de 2016 causou queda de $70 \%$ da produção de castanha na Amazônia (Embrapa, 2017), sendo essa produção um dos pilares econômicos e culturais da RECM.

\section{Material e métodos}

A Resex Chico Mendes (RECM) é uma unidade de conservação federal criada em 1990 (Decreto n. ${ }^{\circ}$ 99.144, de 12/03/1990), com uma área de 970.570ha. Em 2009 ela abrangia 46 seringais e tinha uma população de 10.000 pessoas. Está localizada na região sudeste do estado do Acre, Brasil (Figura 1) e abrange parte dos territórios dos municípios de Rio Branco, Xapuri, Brasiléia, Epitaciolândia, Sena Madureira, Assis Brasil e Capixaba.

Para compreender a dinâmica do desmatamento na RECM foram utilizados dados do Projeto de Monitoramento da Floresta Amazônica por Satélites do Instituto Nacional de Pesquisas Espaciais (Prodes/Inpe) e do projeto Mudança Florestal Global

\footnotetext{
${ }^{1}$ Disponível em:<https://www.facebook.com/550822728310885/videos/1175321755860976/?t=2>. Acesso em 22/11/2018.
} 


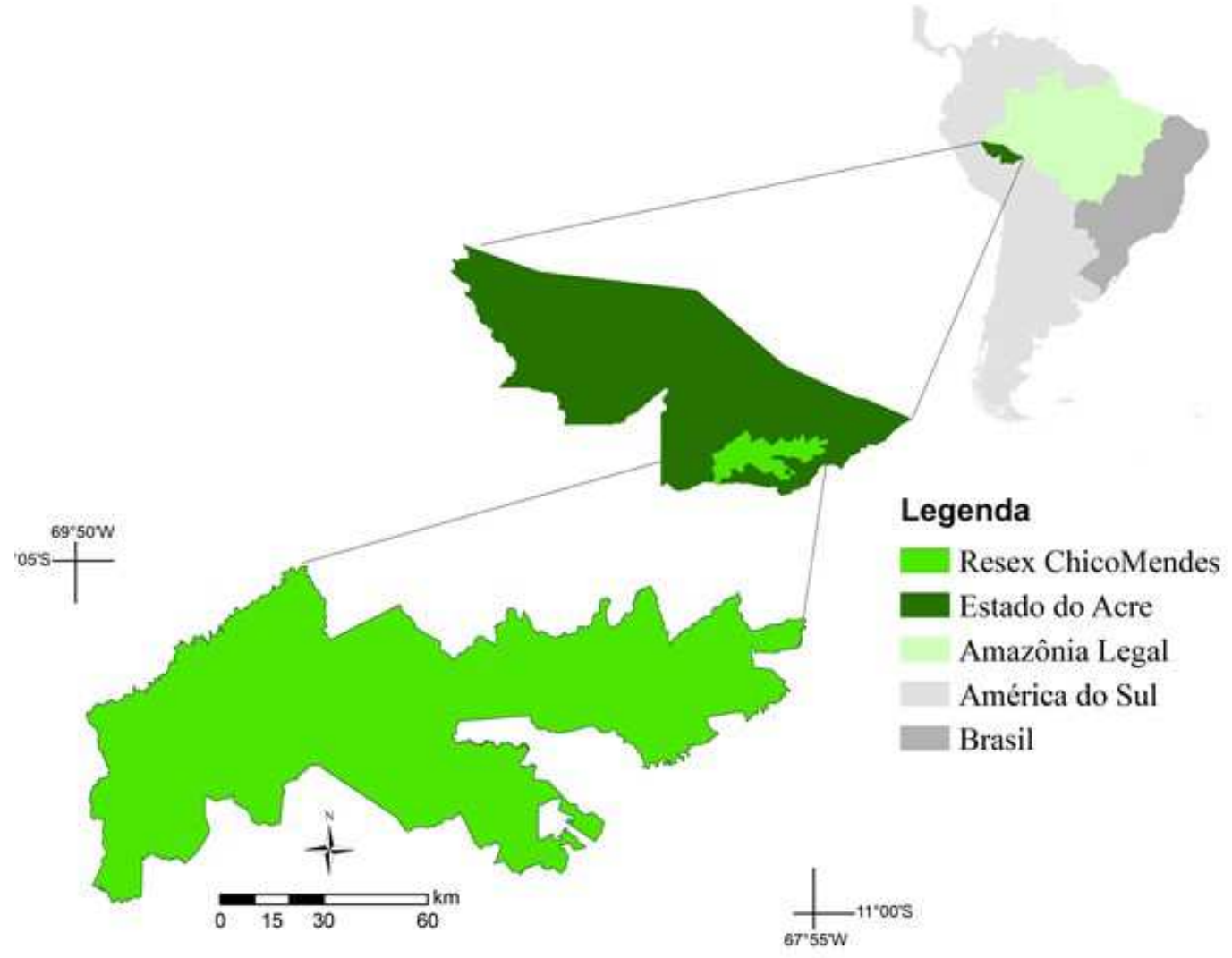

FIGURA 1 - Localização da Reserva Extrativista Chico Mendes em relação à América do Sul, Amazônia Legal e Estado do Acre. FONTE: IBGE e ICMBio.

(Global Forest Change-GFC) da Universidade de Maryland (Hansen et al., 2013). Os dados do Prodes foram acessados no sítio do Inpe ${ }^{2}$ para o período de 1997 a 2016, entretanto com dados anuais somente para 2001 a 2016. Os dados do Projeto $\mathrm{GFC}^{3}$ foram acessados para o período de 2000 a 2016 , entretanto com dados anuais somente para 2001 a 2016. Para analisar as tendências anuais do desmatamento e po- der realizar a comparação entre os dois projetos de monitoramento (Prodes e Hansen) foram utilizados dados anuais no período de 2001 a 2016.

A metodologia Prodes contabiliza o desmatamento com base em polígonos de área mínima de 6,25ha. Entretanto observa-se que há polígonos com áreas inferiores na área de estudo. Na metodologia de Hansen a quantificação dos polígonos

${ }^{2}$ Disponível em: $<$ http://www.dpi.inpe.br/prodesdigital/prodes.php $>$.

${ }^{3}$ Disponível em: <http://www.earthenginepartners.appspot.com/science-2013-global-forest>. 
é feita com resolução espacial de 30 metros $(30 \mathrm{~m}$ x $30 \mathrm{~m}, 900 \mathrm{~m}^{2}$ ou $0,09 \mathrm{ha}$ ), com classificação pixel a pixel. Essa diferença da área mínima mapeável traz implicações para o processo de monitoramento e controle do desmatamento nas unidades de conservação, uma vez que os polígonos desmatados tendem a ser menores em comparação com outras categorias fundiárias.

A perda da cobertura florestal na RECM foi quantificada nos dois métodos mediante a soma do incremento anual do desmatamento no período de 2000 a 2016 com polígonos acima de 1 ha aferidos para a RECM, com base nas seguintes métricas: evolução anual de perda de cobertura florestal da RECM, percentual de desmatamento pela área dos seringais e pelo total de desmatamento da UC, valor absoluto e relativo do desmatamento e da regeneração natural da UC e por seringal. Para medir o ganho de floresta foi feita a comparação da evolução do desmatamento com a evolução da regeneração natural, com uso do método Hansen de 2000 a 2012 na RECM e em nível de seringais individuais. Maiores detalhes sobre os métodos empregados podem ser obtidos em Mascarenhas (2017).

Os dados de ganho de floresta, ou regeneração, foram disponibilizados pelo Projeto GFC para o período de 2000 a 2012 (Hansen et al., 2013). Como há o monitoramento das áreas desmatadas, foi possível analisar estas áreas e verificar se houve o crescimento da vegetação com resposta espectral somente da floresta com o passar dos anos. As áreas de regeneração são comuns na Amazônia; com o esgotamento da fertilidade do solo, os agricultores tendem a abandoná-las.
A análise da dinâmica dos incêndios florestais no período de 1984 a 2015 foi realizada pelo método Índice de Cicatriz de Incêndio (BurnScar Index) BSI, que identifica floresta com copa afetada pelo fogo. Esse método é baseado no processamento de imagens Landsat pelo software CLASlite 3.0. O BSI foi desenvolvido por Alencar (2010) e adaptado por Silva et al.(2018).Para análise dos padrões espaciais e temporais dos incêndios florestais na RECM foram avaliados a área total e anual do impacto do fogo, a área de reincidência do fogo e o tamanho dos polígonos.

Para compreender os padrões de ocorrência dos incêndios florestais, analisamos os incêndios por seringal e por colocação (subdivisões adotadas pelos comunitários para fins de gestão territorial), por acesso terrestre por meio de ramais e pelas fitofisionomias florestais. Maiores detalhes sobre os métodos empregados podem ser obtidos em Mascarenhas (2017).

\section{Resultados e discussão}

\subsection{Dinâmica da cobertura florestal da \\ Reserva Extrativista Chico Mendes}

O desmatamento acumulado na RECM de 1997 a 2016, medido pelo método Prodes, foi de 54.741 ha, correspondendo a $5,6 \%$ de perda de cobertura florestal original como consequência das atividades antrópicas. Em 16 anos (2000 a 2016), o desmatamento aumentou em média $60 \%$ tanto no monitoramento pelo Prodes (3,2 \% da área da RE$\mathrm{CM}$ ) como pelo Hansen (3,5\% da área da RECM). 
TABELA 1 - Distribuição do desmatamento anual pelos métodos Prodes e de Hansen na Reserva Extrativista Chico Mendes, Acre, Brasil, 2001-2016.

\begin{tabular}{ccccc}
\hline \multirow{2}{*}{ ANO } & \multicolumn{2}{c}{ PRODES (2000 A 2016) } & \multicolumn{2}{c}{ HANSEN - GFC (2000 A 2016) } \\
\cline { 2 - 5 } & Desmatamento (ha) & Polígonos & Desmatamento (ha) & Polígonos \\
\hline $\mathbf{2 0 0 1}$ & 2.890 & 878 & 1367 & 590 \\
$\mathbf{2 0 0 2}$ & 1.125 & 355 & 1.014 & 449 \\
$\mathbf{2 0 0 3}$ & 3.889 & 1.004 & 871 & 394 \\
$\mathbf{2 0 0 4}$ & 4.462 & 1.147 & 1.670 & 739 \\
$\mathbf{2 0 0 5}$ & 4.065 & 1.341 & 5.317 & 1.495 \\
$\mathbf{2 0 0 6}$ & 1.363 & 498 & 1.023 & 459 \\
$\mathbf{2 0 0 7}$ & 277 & 28 & 718 & 381 \\
$\mathbf{2 0 0 8}$ & 1.301 & 129 & 1.403 & 696 \\
$\mathbf{2 0 0 9}$ & 418 & 54 & 990 & 530 \\
$\mathbf{2 0 1 0}$ & 738 & 87 & 1.113 & 498 \\
$\mathbf{2 0 1 1}$ & 1.275 & 156 & 1.648 & 747 \\
$\mathbf{2 0 1 2}$ & 1.338 & 151 & 3.086 & 1.165 \\
$\mathbf{2 0 1 3}$ & 1.212 & 131 & 2.722 & 1.191 \\
$\mathbf{2 0 1 4}$ & 2.468 & 254 & 3.675 & 1.468 \\
$\mathbf{2 0 1 5}$ & 1.644 & 178 & 3.130 & 1.390 \\
$\mathbf{2 0 1 6}$ & 3.018 & 440 & 4.354 & 1.699 \\
TOTAL & $\mathbf{3 1 . 4 8 5}$ & $\mathbf{6 . 8 3 1}$ & $\mathbf{3 4 . 1 0 2}$ & $\mathbf{1 3 . 8 9 1}$ \\
\hline
\end{tabular}

O crescimento do desmatamento no período de 2001 a 2016 para o Prodes foi de 31.485ha e para Hansen foi de 34.102ha, distribuídos em 6.831 e 13.891 polígonos de desmatamento, respectivamente (Tabela 1).

Em termos percentuais, a sobreposição de polígonos coincidentes nas mesmas áreas entre Prodes e Hansen foi de $60 \%$. Os anos com maior diferença na tendência anual do desmatamento foi entre 2003 e 2004, em que a estimativa da área do Prodes foi três vezes maior que a de Hansen e o número de polígonos duas vezes maior que o do método de Hansen (7.954ha Prodes e 2.541ha Hansen, 2.151 polígonos Prodes e contra 1.133 polígonos Hansen)
(Figura 2). Para o método Hansen, 2005 foi o pico do desmatamento para a RECM (5.317 ha/ano); para o método Prodes o pico ocorreu em 2004 (4.462 ha/ ano) (Figura 2).

O incremento do desmatamento de 2011 a 2014medido por Hansen ficou em torno de duas vezes maior e abrangeu sete vezes mais polígonos que o Prodes (11.131ha com 4.571 polígonos Hansen; 6.293ha com 692 polígonos - Prodes). As estimativas dos anos de 2015 e 2016 mostram que os métodos convergem para uma trajetória ascendente do desmatamento, somando mais 4.662ha no Prodes e 7.484ha em Hansen. 


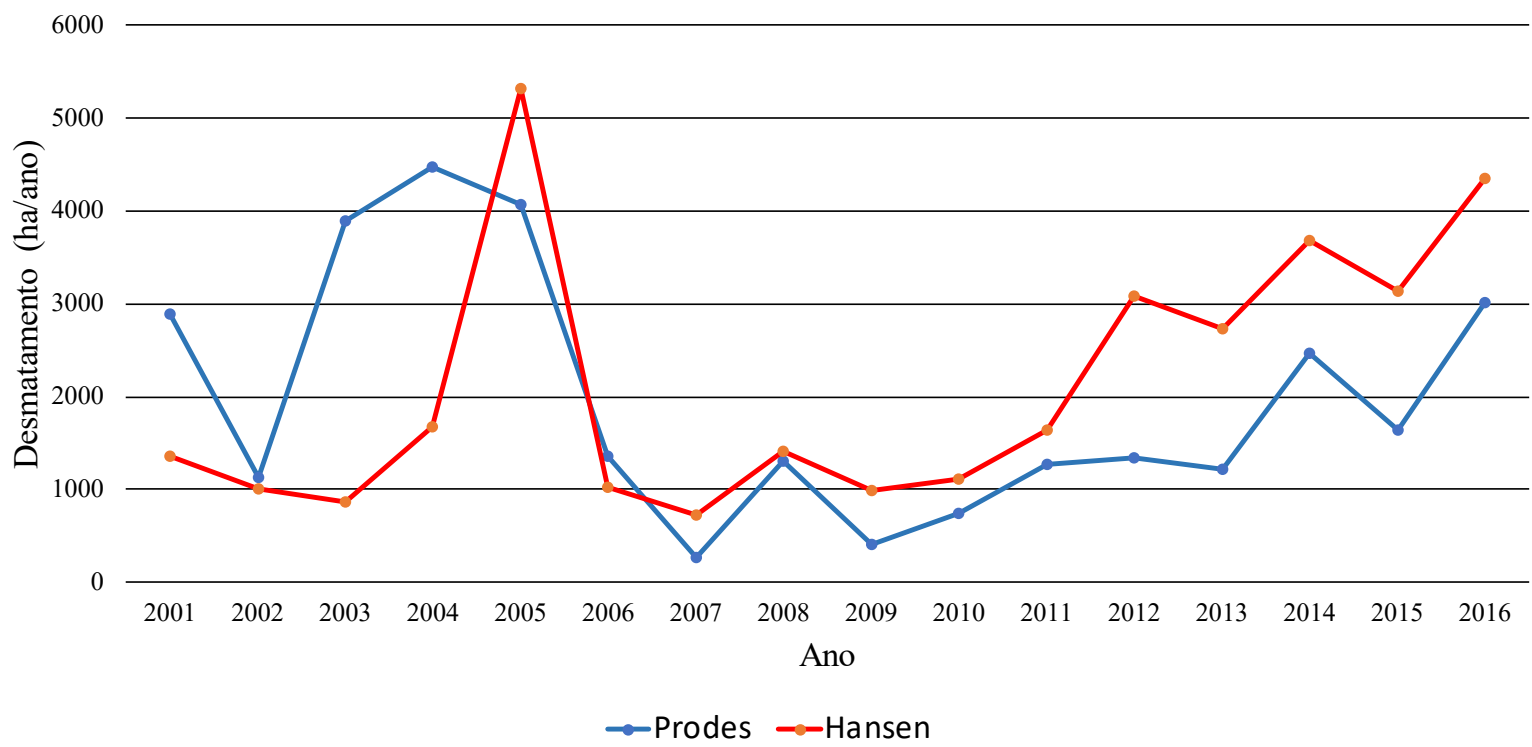

FIGURA 2 - Evolução da taxa de desmatamento anual medida pelos métodos Prodes e Hansen na Reserva Extrativista Chico Mendes, Acre, Brasil, 2001-2016.

Os resultados obtidos pelo Prodes e por Hansen no período de 2001 a 2016 demonstram que a dinâmica da perda de floresta é flutuante (Ewers et al., 2008). Houve uma forte perda de florestaentre2001 a 2004, coincidindo com a consolidação do Plano Real, construção e pavimentação de rodovias e expansão do agronegócio (Alencar, 2004; Fearnside, 2006; Soares-Filho et al., 2005), declinando entre 2006 a 2011 e ganhou força novamente a partir de 2012, o que coincidiu com a entrada em vigor do novo Código Florestal Brasileiro (Lei n. ${ }^{\circ}$ 12.651, de 25 de maio de 2012). Os pulsos de desmatamento e as decisões de mudanças de uso da floresta estão associados às culturas agrícolas, à pecuária e às decisões políticas (Fearnside, 2006).

Presumia-se que os dados sobre desmatamentos de Prodes e de Hansen seguiriam tendências similares de aumento e redução. Entretanto isso não ocorreu (Figura 2). Para Richards et al. (2017) existe uma ligação intrínseca entre a quantidade e a forma como os polígonos de desmatamento são contabilizados, mostrando que as medidas diferentes se explicam em função das diferenças entre as duas metodologias. Para Milodowski et al. (2017), isso pode estar relacionado a diferentes definições e objetivos de cada método, pois se verifica que as taxas de desmatamento medidas pelo Prodes são sistematicamente mais baixas do que as de Hansen.

Na RECM houve uma mudança no padrão de distribuição do tamanho dos polígonos de desmatamento (Figura 3). No período de 2001 a 2005 ainda eram registrados desmatamentos maiores que 100ha, entretanto com tamanho médio de 3 ha. Após 2011, os grandes polígonos reduziram para 50ha, entretanto o tamanho médio mais que dobrou, passando a ser de 8ha. Complementar a isso, no 


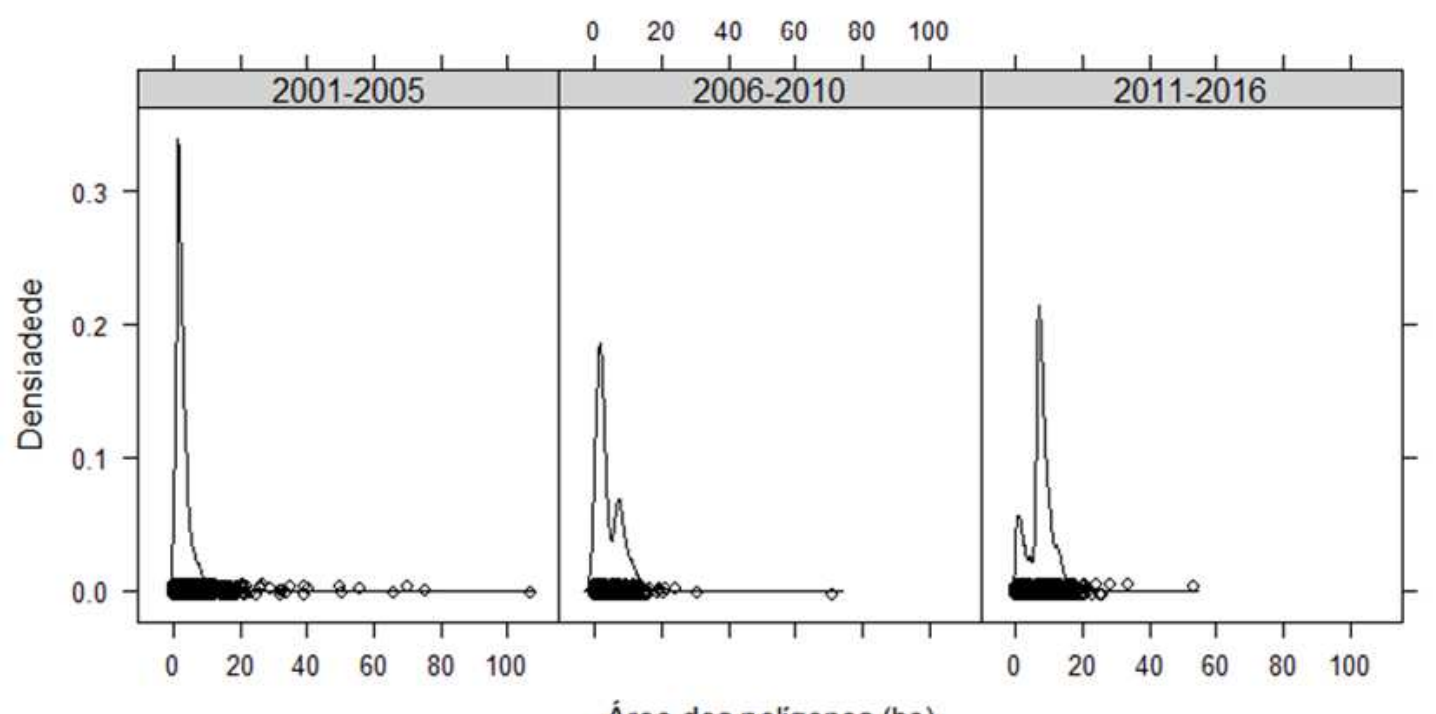

Área dos poligonos (ha)

FIGURA 3 - Padrão de distribuição do tamanho dos polígonos de desmatamento na Resex Extrativista Chico Mendes no período de 2001 a 2016.

período de 2011 a 2016 foi observado que 92\% dos polígonos de desmatamento são continuação das áreas já existentes, evidenciando a tendência de pecuarização abordada por Gomes et al. (2012) e Hoelle (2015).

Não há evidências de que os desmatadores tenham mudado de estratégia, com desmates de pequenas áreas inferiores a $6,25 \mathrm{ha}$, para não serem detectados pelo Prodes, como defendem Richards et al. (2017). Porém grande parte do aumento do desmatamento coincide com a entrada em vigor do novo Código Florestal em 2012 (Lei n. ${ }^{\circ} 12.651$, de 25 de maio de 2012), que revogou o Decreto Federal n. ${ }^{\circ} 6.514$, de 22 de julho de 2008 ao oferecer anistia de multas aos desmatadores ilegais e retirar a obrigação de recuperar áreas com desmatamentos ilegais ocorridos até 2008 (Nobre, 2014).
Outro desafio para a gestão da RECM é complementar o monitoramento da floresta com outras ações que verifiquem as condições florestais e de serviços ecossistêmicos, como o monitoramento da biodiversidade in loco e participativo, com participação de moradores, gestores e comunidade cientifica. $\mathrm{O}$ desmatamento na RECM tem sido causado pela pecuária, movida pela ampliação da infraestrutura de ramais (estradas de terra) localizada principalmente na zona de influência da rodovia BR-317 e dos centros urbanos. A ocupação irregular da terra é crítica nessas áreas e estimula o desmatamento para formação de pastos, assim como ocorre em outras partes da Amazônia (Araújo et al., 2015; Gomes et al., 2012) (Figura 4).

Os seringais próximos à rodovia, aos ramais e aos centros urbanos de Brasiléia, Epitaciolândia 


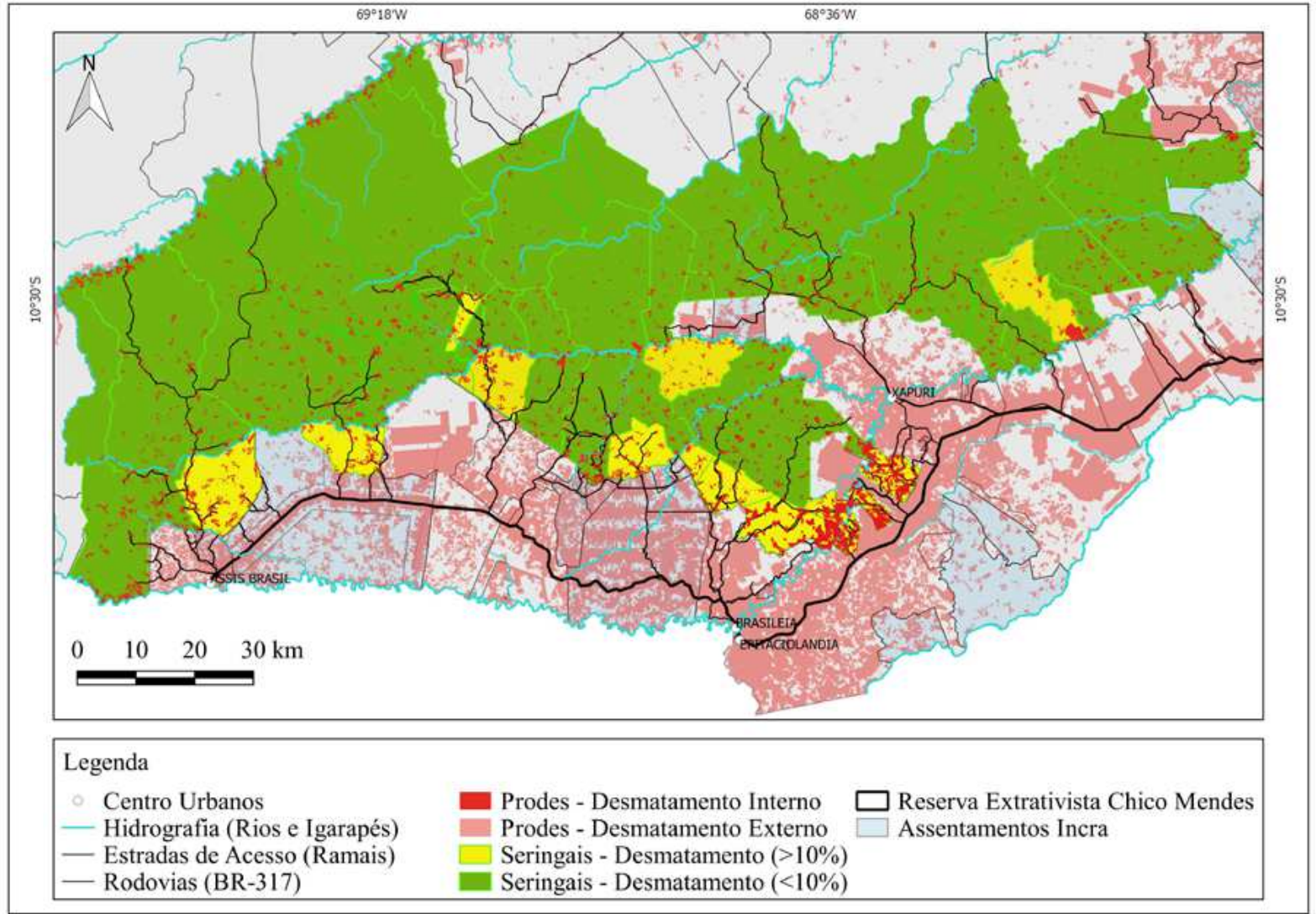

FIGURA 4 - Desmatamento acumulado na Reserva Extrativista Chico Mendes até 2014.

FONTE: Prodes.

e Xapuri têm maiores áreas desmatadas do que os demais seringais. Eles contêm áreas com práticas agrícolas e pecuárias de médio porte, incompatíveis com o objetivo extrativista da unidade (Figura 4).

A concentração de desmatamento próximo a rodovias e ramais é um padrão semelhante ao proposto na teoria de Von Thünen, que relaciona o aumento do desmatamento com a expansão agrícola, a expansão de pastagem para a criação de gado e a abertura de novas estradas (Vanwey et al., 2009; Soares-Filho et al., 2010).
Oliveira (2013) demonstrou que as estradas e ramais explicam $81 \%$ do desmatamento no interior da RECM. Em torno de 10 seringais têm mais de $10 \%$ de suas áreas desmatadas. Isso descumpre o Plano de Utilização da Resex Chico Mendes, que recomenda ocupar menos de $10 \%$ da área de posse para atividades complementares. Outras atividades não podem ultrapassar o tamanho máximo de $30 \mathrm{ha}$. No caso de atividades que superem esse limite, é obrigatória a recuperação da área (Brasil, 2008, p. 6). 


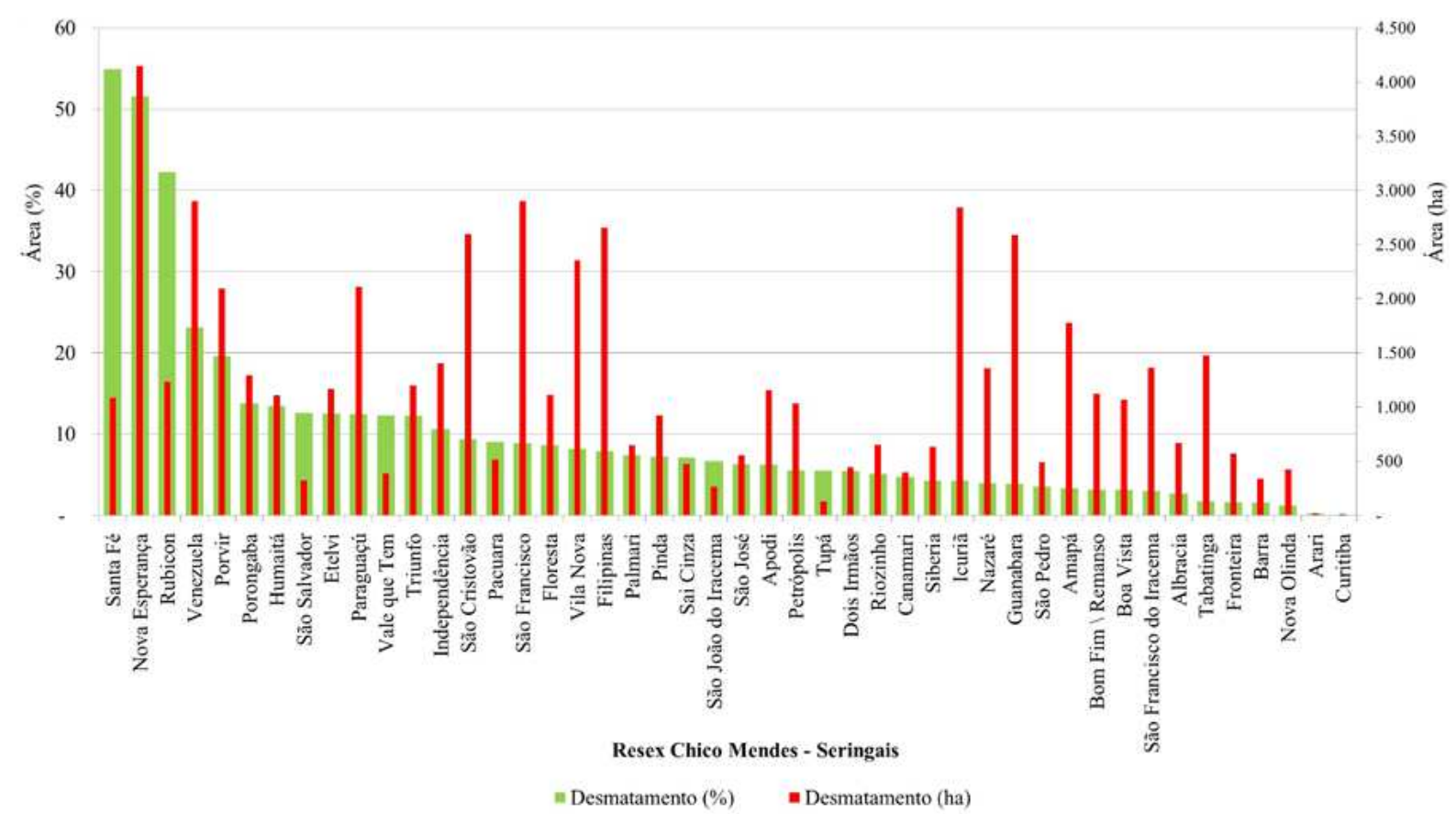

FIGURA 5 - Comparação entre os níveis percentuais e os números absolutos de desmatamento nos seringais da Reserva Extrativista Chico Mendes até 2016.

FONTE: Prodes.

Os seringais que proporcionalmente mais perderam cobertura florestal entre 1988 e 2014 foram Nova Esperança (52\%), Santa Fé (55\%) e Rubicon (42\%). Os seringais São João do Iracema $(0 \%)$, Tupá $(0 \%)$, Arari ( $0 \%)$, Curitiba ( $0 \%$ ) mantiveram a cobertura florestal quase intocada (Figura 4). Em números absolutos, os seringais que mais desmataram foram Nova Esperança (4.148ha), Venezuela (2.900ha), São Francisco (2.898ha), Icuriã (2.842ha) e Filipinas (2.597ha). Estes quatro últimos seringais, apesar de a área desmatada ser maior em número absoluto, proporcionalmente, suas áreas têm menos de $10 \%$ do seringal desmatado (Figura 5).
Com exceção do seringal Nova Esperança, os seringais com áreas inferiores a 3.000 ha e que estão com níveis de desmatamento acima de $40 \%$ têm desmatamentos menores que 1.500ha em números absolutos (Figura 5; Apêndice A e B). Para os seringais com área superior a $25.000 \mathrm{ha}$, os percentuais de perda da cobertura florestal estão abaixo de $10 \%$, mas existem desmatamentos maiores que 2.000ha (Figura 5, Apêndices A e B). O seringal Nova Esperança é o que apresenta as maiores perdas de cobertura florestal, tanto em números absolutos como em números relativos; ele é responsável por $7 \%$ do desmatamento total da RECM (Figura 5; Apêndice B). 


\subsection{Dinâmica da regeneração florestal na Reserva Extrativista Chico Mendes}

O ganho de floresta pelo processo de regeneração natural na RECM foi de 2.712 ha, correspondendo a $10 \%$ do desmatamento total e $0,3 \%$ de sua área total. Os seringais com as maiores áreas em situação de regeneração em relação à porcentagem de áreas desmatadas são: São João (70\%), Independência (58\%), Dois Irmãos (40\%), Petropólis (35), Tupá (34\%), Floresta (34\%), Albracia (33\%), Sibéria (32\%), Palmari (27\%), São Pedro (27\%), Barra (24\%), Fronteira (23\%) e Boa Vista (21\%). Em todos esses seringais a área desmatada fica abaixo de 500ha (Figura 6; Apêndice C).

Os seringais com maiores áreas de regeneração são Guanabara (2.000ha), São Francisco (1.584ha), Icuriã (1.460ha), Filipinas (1.436ha), São Cristovão (1.154ha), Amapá (1.069ha), Paraguaçú (1.008ha), que representam 7 a 17\% da área em regeneração da RECM (Figura 6; Apêndice D). Os seringais Nova Esperança e Santa Fé, os mais desmatados, têm somente 60 ha e 8 ha de regeneração natural, respectivamente (Figura 6; Apêndice C). Os seringais com maiores áreas e percentuais de desmatamento abandonam/investem menores áreas para regeneração natural, devido à consolidação da pecuária de corte, associada à desvalorização dos produtos extrativistas como a castanha e látex da seringueira.

$\mathrm{O}$ ganho de floresta medido pelo método Hansen na RECM mostra uma baixa eficiência na detecção da regeneração, entretanto pode ser usado com indicador desse processo. Análises de imagens de satélite mostraram que a regeneração foi maior que o estimado por Hansen. É recomendada verificação de campo para acompanhamento e monitoramento in loco da sucessão florestal pelas instituições gestoras da RECM e de monitoramento como Inpe, Unidade Central de Geoprocessamen-

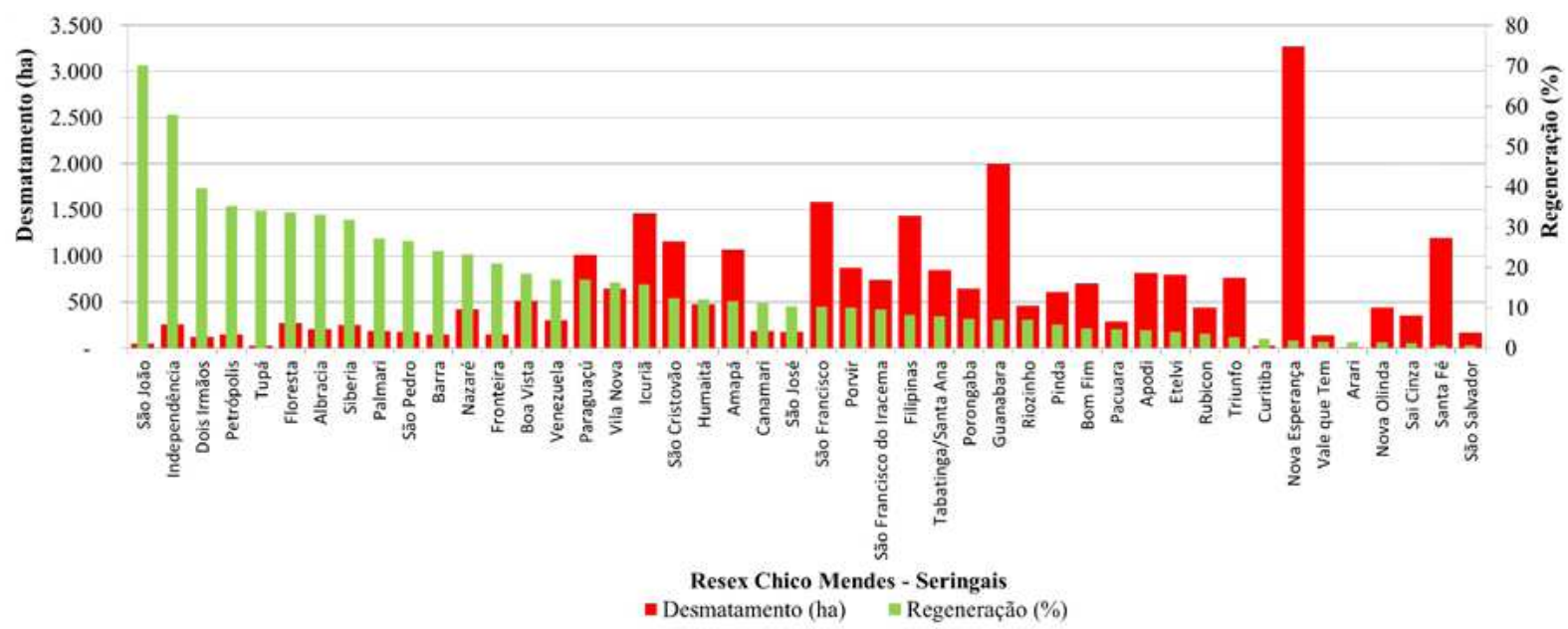

FIGURA 6 - Percentuais de ocorrências de áreas com regeneração natural da floresta em relação às áreas desmatadas respectivas nos seringais da Reserva Extrativista Chico Mendes até 2012.

FONTE: Método Hansen (GFC). 
to e Sensoriamento Remoto do Estado do Acre (Ucegeo) e Universidades. Do ponto de vista da dinâmica florestal, o período de 12 anos monitorado por Hansen é curto e não caracteriza uma recuperação que faça a vegetação chegar ao status de floresta, entretanto mostra áreas com potencial de recuperação importantes para sucessão ecológica (Chazdon, 2016). D'Oliveira et al. (2011) estimam que a recuperação integral da biomassa florestal removida na região do Estado do Acre dure em torno de 20 a 30 anos.

Mesmo com a detecção de $10 \%$ da regeneração de floresta nas áreas desmatadas, a RECM mantém $94 \%$ de cobertura florestal. Isso corrobora as argu- mentações de que as áreas protegidas são barreiras ao avanço do desmatamento (Barber et al., 2014; Nepstad et al., 2006; Numata \& Cochrane, 2012; Pfaff et al., 2014; Soares-Filho et al., 2010; Yanai et al., 2012; Vitel et al., 2013).

\subsection{Dinâmica das ocorrências de incêndios florestais na Reserva Extrativista Chico Mendes}

Os incêndios florestais na RECM no período de 1984 a 2015 impactaram uma área de 50.363ha (Figura 6), sendo que os anos de 2005 e 2010 pre-

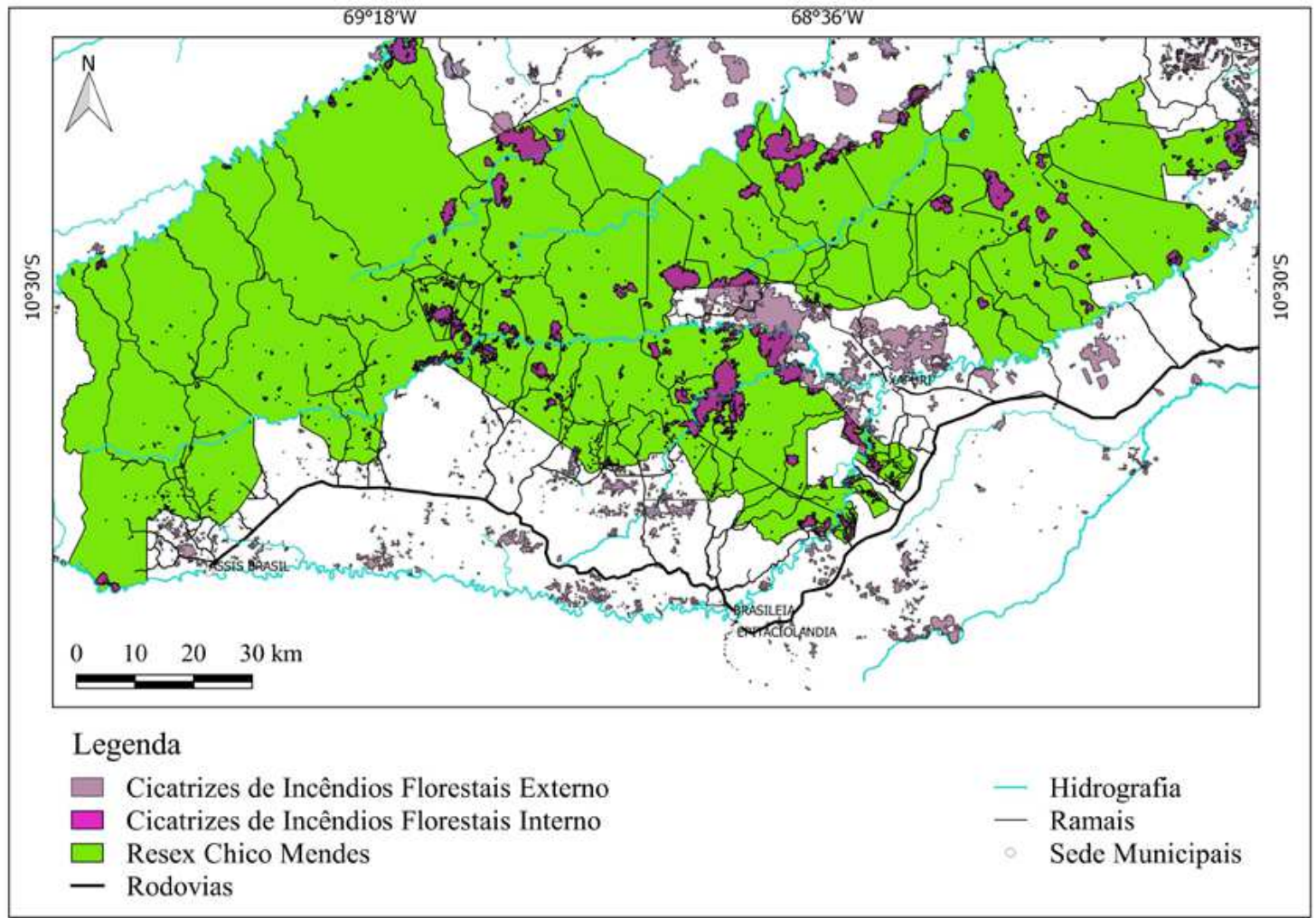

FIGURA7 - Cicatrizes de incêndios florestais que atingiram a Reserva Extrativista Chico Mendes, entre 1984 e 2015. FONTE: Silva et al. (2018). 
dominaram no total (Figura 7). Segundo dados do Prodes, a área de desmatamento até 2015 na reserva foi de $51.723 \mathrm{ha}$, similar em tamanho à de florestas impactadas pelo fogo. Esse paralelo ressalta a vulnerabilidade da floresta ao fogo, colocando no mesmo patamar do desmatamento, em termos de área.

Os anos com os maiores impactos causados por incêndios florestais foram 2005, com 41.569 ha, e 2010 , com 9.610 ha, representando $80 \%$ e $19 \%$, respectivamente, do total das cicatrizes de incêndios da RECM (Figura 8). O regime do fogo na RECM corresponde aos anos de secas extremas, em que a Amazônia Sul-Ocidental foi o local dos epicentros da seca causada pelo aquecimento anômalo do Oceano Atlântico Tropical (Lewis et al., 2011). Historicamente, as secas que afetam a Amazônia ocasionando incêndios florestais são causadas por El Niño (Alencar et al., 2015; Brown et al., 2011; Silva et al., 2018), não afetando de forma significativa a Amazônia Sul Ocidental, onde está localizada a RECM. Esses anos de secas demostraram o quanto o clima pode transformar ações de queimas cotidianas para os agricultores em situação de catástrofe para a floresta. Os incêndios florestais na RECM tiveram origem em queimadas antrópicas com tamanho médio de 25 ha.

Entre 1992 e 1997 não houve registro de incêndios florestais. Após 2005, os incêndios florestais passaram a ser uma realidade preocupante para a proteção e gestão de unidades de conservação no Acre. O período seco tem se prolongado desde $1979 \mathrm{em} 6,5$ dias $\pm 2,5$ por década (Fu et al., 2013) e as projeções futuras apontam para o aumento da frequência de eventos climáticos extremos (IPCC, 2012).

Após o primeiro grande incêndio florestal, em 2005, moradores e gestores passaram a se preocupar com outros incêndios. Isso levou, em 2008, à revisão do Plano de Utilização da RECM, que passou a incluir medidas preventivas ligadas ao uso do fogo:

O uso do fogo deve ser evitado ao máximo pelos moradores que, em caso de necessidade extrema, deverão tomar todos os cuidados, sempre aguardando as primeiras chuvas. Deverão fazer aceiros de no mínimo 2 metros e organizar mutirão que permaneça no local até que se tenha certeza que o fogo está completamente apagado, sendo o controle do fogo responsabilidade do morador da colocação (BRASIL, 2008, p. 5).

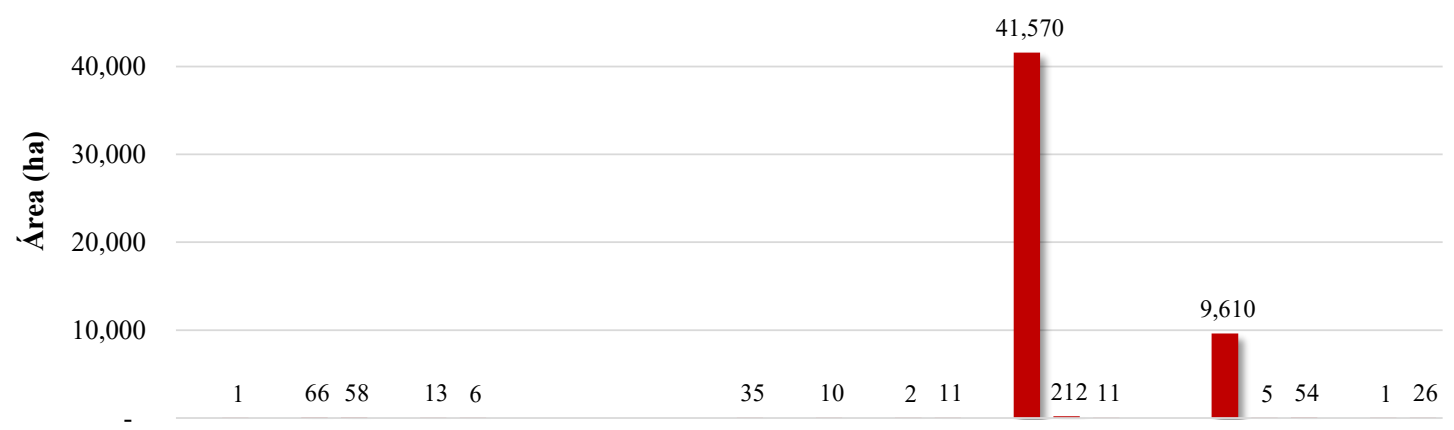

$8485868788 \quad 899091929394959697989900010203040506 \quad 0708 \quad 091011 \quad 12 \quad 13 \quad 14 \quad 15$

FIGURA 8 - Evolução anual da área impactada por incêndios florestais na Reserva Extrativista Chico Mendes, 1984 a 2015. 
Ao longo dos 32 anos de monitoramento das cicatrizes de incêndios florestais, algumas áreas queimaram mais de uma vez. Essas áreas de reincidência do fogo representaram $3 \%$ do total (Tabela 2). A degradação florestal pelo fogo causa mortalidade e degradação das árvores (Brando et al., 2014; Longo et al., 2016) e pode influenciar a tomada de decisão do agricultor em manter a floresta em pé ou desmatá-la (Silva et al., 2018). O percentual de cicatrizes de incêndios florestais em área desmatada foi de $6 \%$ até 2016 , e para as cicatrizes que queimaram duas ou mais vezes foi de $10 \%$.

Foram mapeados 11 polígonos de incêndios florestais maiores que $1.000 \mathrm{ha}$ em 2005 e 2010 na
RECM, sendo oito polígonos em 2005 e três em 2010. O maior polígono identificado foi de 5.274ha, em 2005. Os grandes polígonos representam 52\% do total dos incêndios, evidenciando a vulnerabilidade da floresta ao fogo (Figura 9). Cerca de $86 \%$ dos polígonos de incêndios florestais são maiores que 100ha, ressaltando o quão intensos e devastadores foram os incêndios florestais de 2005 e 2010 . Observando os registros de precipitação da estação pluviométrica de Rio Branco, houveram 69 dias consecutivos sem chuva em 2005, tornando a floresta muito seca e vulnerável a incêndios.

A maior parte dos polígonos $>1.000$ ha estão localizados na região sudeste da RECM, onde há

TABELA 2 - Reincidência dos incêndios florestais e desmatamento posterior das florestas queimadas na Reserva Extrativista Chico Mendes.

\begin{tabular}{ccccc}
\hline Reincidência & $\begin{array}{c}\text { Área de incêndios } \\
\text { florestais (ha) }\end{array}$ & $\begin{array}{c}\text { \% em relação ao } \\
\text { total de incêndios } \\
\text { florestais }\end{array}$ & $\begin{array}{c}\text { Área de desmata- } \\
\text { mentos ligados a } \\
\text { incêndios(ha) }\end{array}$ & $\begin{array}{c}\text { \% em relação ao total de } \\
\text { desmatamento ligados a } \\
\text { incêndios }\end{array}$ \\
\hline 1 & 49.053 & 97 & 3.214 & 6 \\
2 & 1.310 & 3 & 129 & 10 \\
Total & $\mathbf{5 0 . 3 6 3}$ & $\mathbf{1 0 0}$ & $\mathbf{3 . 3 4 3}$ & $\mathbf{7}$ \\
\hline
\end{tabular}

FONTE: Silva et al. (2018).

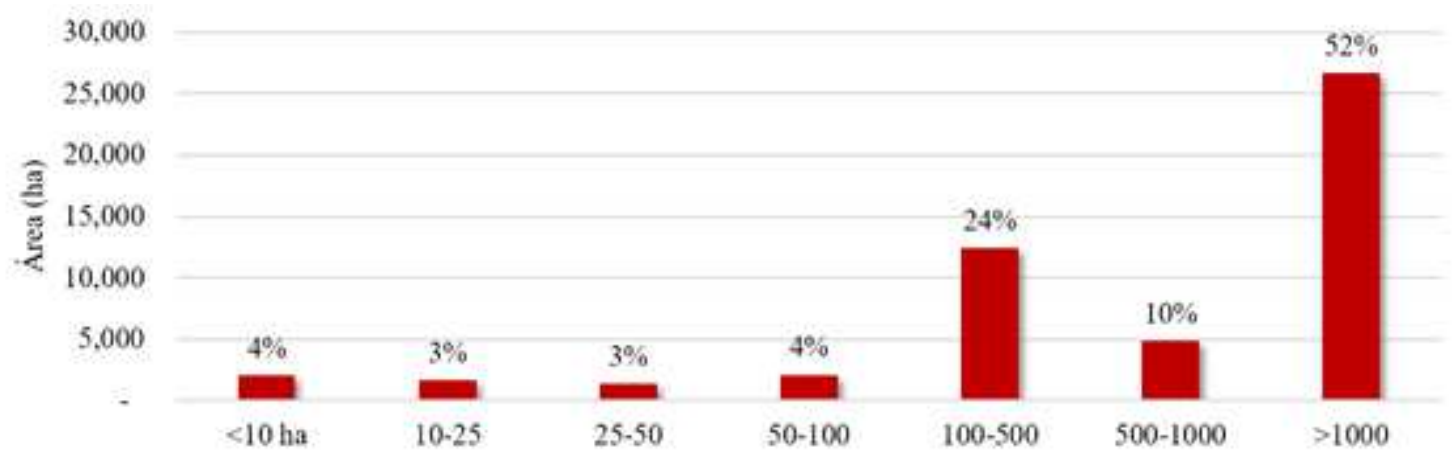

FIGURA 9 - Distribuição dos incêndios florestais por classe de tamanho dos polígonos na Reserva Extrativista Chico Mendes no período 1984-2015. 
maior concentração do desmatamento e acesso por estradas (Figuras 7 e 9). Entretanto a outra metade dos grandes polígonos está em regiões de difícil acesso terrestre e com número menor de colocações (Figuras 7 e 10). A baixa densidade populacional também pode ser um fator de vulnerabilidade aos incêndios, devido à falta de combate e controle do fogo, que permitiu o alastramento dos incêndios por grandes áreas, especialmente na região norte da RECM, nas proximidades dos rios Iaco e Riozinho do Rola. Nesta região, os incêndios originaram de áreas desmatadas de no máximo 30ha, demostrando que, a partir de pequenas queimadas, o fogo pode sair do controle e queimar milhares de hectares de floresta na RECM.

Os incêndios florestais concentraram-se na região central e leste da RECM, entre os municípios de Xapuri, Rio Branco e Epitaciolândia (Figura 9). Os municípios de Assis Brasil e parte de Brasiléia têm as menores quantidades de cicatrizes de incêndios florestais; entretanto a quantidade de colocações é semelhante à das regiões com alta quantidade de incêndios. Uma possível explicação para esse cenário é a maior sensibilização e conscientização dos produtores em regiões distintas da RECM.

As fitofisionomias florestais mais afetadas pelo fogo são as florestas abertas com bambu, com cerca de 53\%dos incêndios, seguidas pelas florestas aluviais $(20 \%)$ e florestas abertas com palmeira. Em verificação de campo, observou-se que a serrapilheira da floresta com bambu perde umidade rapidamente, favorecendo o espalhamento do fogo. Entretanto essa observação necessita ser testada cientificamente.

\section{Conclusão}

A avaliação do sucesso ou do fracasso da RECM depende do contexto e de quem está avaliando. Em termos de cobertura florestal, a RECM ainda tem 94\% dela. Mas, quando se analisam seringais específicos, o problema do desmatamento fica claro: ele está concentrado em alguns seringais, dois dos quais perderam mais de $50 \%$ de sua cobertura

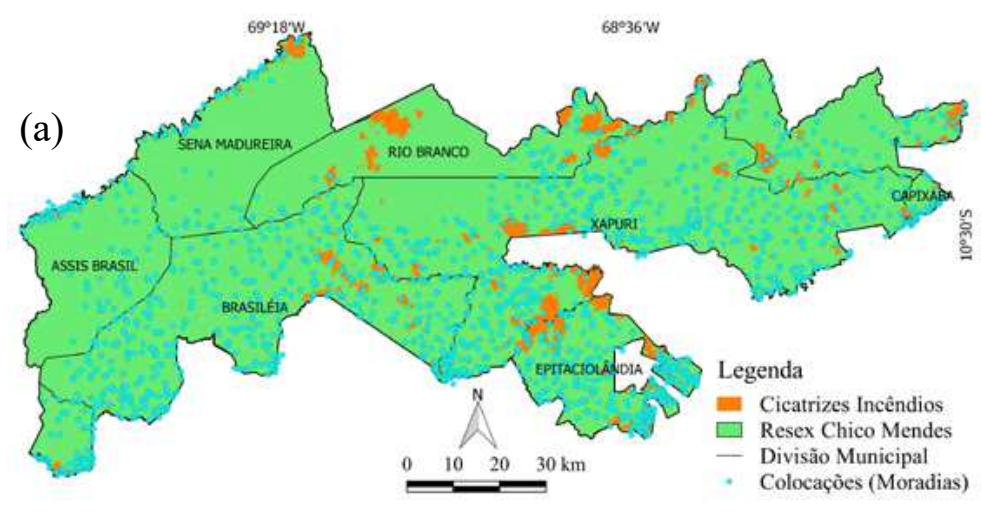

(b)

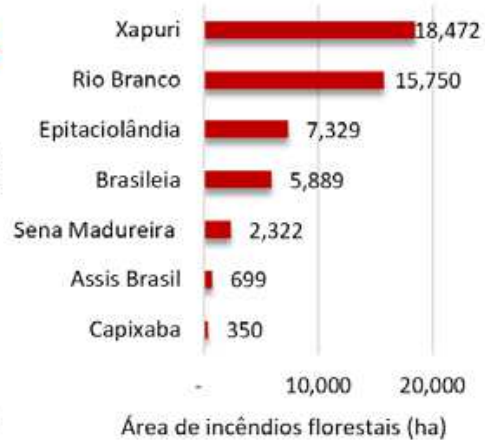

FIGURA 10 - Distribuição dos incêndios florestais e das colocações na Reserva Extrativista Chico Mendes, por municípios, Acre, Brasil, 1984-2015. 
florestal. Com a ampliação das áreas desmatadas associadas à forte cadeia da pecuária e desvalorização das cadeias extrativistas, seringais com mais de $20 \%$ de desmatamento podem se tornar a norma para a RECM.

O uso de mais de uma fonte de estimativas de desmatamento pode complicar a gestão da RECM, mas fornece mais confiança nos resultados. Dados do Prodes e do método Hansen mostram que, nos últimos anos, a taxa de desmatamento na RECM está crescendo, mesmo que os valores absolutos difiram significativamente uns dos outros. O Prodes faz o monitoramento oficial no Brasil e detém o histórico do desmatamento desde 1988. Ele pode ser complementado pelos dados de Hansen, o que aumenta as ferramentas gratuitas para monitoramento e fiscalização. A disponibilidade gratuita dos dois sistemas de estimativas de desmatamento ajuda a criar mais transparência nas análises e permite que mais grupos tenham acesso a eles; mas exige clareza na maneira de divulgar os dados.

Mesmo com a subestimação detectada por Hansen para a regeneração florestal, nota-se que está havendo recuperação da vegetação após o abandono das áreas utilizadas pelas atividades agropecuárias. Em torno de 43 seringais apresentam regeneração natural da mata. A exceção reside nos seringais Nova Esperança, Santa Fé e Rubicon, que precisarão de intervenções dos órgãos gestores juntamente aos seringueiros.

A partir de 2005, uma nova realidade instalou-se na RECM: os incêndios florestais. Eles já afetaram uma área quase equivalente à desmatada na RECM. Secas severas podem fazer a RECM ser um palco de incêndios florestais, um perigo potencial para o qual as evidências indicam crescimento nos próximos anos e décadas. Esses incêndios podem ocorrer em qualquer parte da RECM e é necessário um programa efetivo de prevenção para evitá-los.

A RECM ainda serve como exemplo de sucesso de manutenção da sua cobertura florestal no contexto global em face do perigo de um tipping point no clima regional. Porém as altas taxas de desmatamento em alguns seringais indicam que esse sucesso pode ser temporário. De uma certa maneira, a RECM representa um indicador de como estamos vivendo num planeta finito. A transformação da realidade da RECM é um processo contínuo e precisa ser compreendido para criar soluções que funcionem nas suas diversas dimensões - social, ambiental e cultural.

\section{Agradecimentos}

Ao Instituto Chico Mendes de Conservação da Biodiversidade (ICMBio); ao Setor de Estudos do Uso da Terra e de Mudanças Globais (Setem) do Parque Zoobotânico da Universidade Federal do Acre;à Fundação de Amparo à Pesquisa do Estado do Acre pelo financiamento parcial (Edital 03/2013).

\section{Referências}

Alencar, A. O desenvolvimento que queremos: ordenamento territorial da BR-163, Baixo Amazonas, Transamazônica e Xingu. In: Relatório do Encontro. Maio, 29-31.[IPAM, ISA, FVPP, Fetagri, BAM, FORMAD, FVPP, CEFTBAM, Fórum BR-163, GTA (Orgs.)], Santarém, PA, 2004.

Alencar, A. Spatial and temporal determinants of forest fires on the Amazonian deforestation frontier: Implications for current and future carbon emissions. Tese de Doutorado, Gainesville, Flórida: University of Florida, 2010, 153 p. 
Alencar, A. A.; Brando, P. M.; Asner, G. P.; Putz, F. E. Landscape fragmentation, severe drought, and the new Amazon forest fire regime. Ecological Applications, 25(6), 1493-1505, 2015. doi: 10.1890/14-1528.1, 2015

Aragão, L. E. O. C.; Anderson, L. O.; Fonseca, M. G.; Rosan, T. M.; Vedovato, L. B.; Wagner, F. H. et al. 21st Century drought-related fires counteract the decline of Amazon deforestation carbon emissions. Nature Communications, 9, 536, 2018. Doi: 10.1038/s41467-017-02771-y

Araújo, E.; Barreto, P.; Martins, H. Áreas protegidas críticas na Amazônia no período de 2012 a 2014. p. 20. Belém: IMAZON, 2015.

Baccini, A.; Walker, W.; Carvalho, L.; Farina, M.; Sulla-Menashe, D.; Houghton, R. A. Tropical forests are a net carbon source based on aboveground measurements of gain and loss. Science, 358, 2017. doi: 10.1126/science.aam5962

Barber, C. P.; Cochrane, M. A.; Souza Jr., C. M.; Laurance, W. F. Roads, deforestation, and the mitigating effect of protected areas in the Amazon. Biological Conservation, 177, 203-209, 2014. doi: 10.1016/j.biocon.2014.07.004

Brando, P. M.; Balch, J. K.; Nepstad, D. C.; et al. Abrupt increases in Amazonian tree mortality due to drought-fire interactions. Proceedings of the National Academy of Sciences, 111(17), 6347-6352. doi: 10.1073/pnas.1305499111, 2014

Brasil. Plano de Utilização da Reserva Extrativista Chico Mendes-Portaria n. ${ }^{\circ}$ 60, de 28 de agosto de 2008, Brasília: ICMBio, 2008.

Brienen, R. J. W.; Phillips, O. L.; Feldpausch, T. R.; Gloor, E.; Baker, T. R. et al. Long-term decline of the Amazon carbon sink. Nature, 519, 344-348, 2015. doi: 10.1038/ nature 14283

Brown, I. F.; Nepstad, D. C.; Pires, I. de O.; Luz, L. M.; Alechandre, A. S. Carbon Storage and Land-use in Extractive Reserves, Acre, Brazil. Environmental Conservation, 19, 307-315, 1992. doi: 10.1017/S0376892900031428

Brown I. F.; Schroeder W.; Setzer A.; De Los Rios Maldonado M.; Pantoja N.; Duarte A.; Marengo J. Monitoring fires in southwestern Amazonia Rain Forests. Eos, Transactions American Geophysical Union, 87, 253-259. 2011. doi: 10.1029/2006EO260001
Ceballos, G.; Ehrlich, P. R.; Dirzo, R. Biological annihilation via the ongoing sixth mass extinction signaled by vertebrate population losses and declines. Proceedings of the National Academy of Sciences, 114, E60809-E6096. 2017. doi: 10.1073/pnas.1704948114

Chazdon, R. L. Renascimento de florestas: regeneração na era do desmatamento. São Paulo: Oficina de textos, 2016.

D'Oliveira, M. V. N.; Alvarado, E. C.; Santos, J. C.; Carvalho Jr., J. A. Forest natural regeneration and biomass production after slash and burn in a seasonally dry forest in the Southern Brazilian Amazon. Forest Ecology and Management, 261(9), 1490-1498, 2011. doi: 10.1016/j. foreco.2011.01.014

Embrapa. Pesquisa aponta queda de $70 \%$ na produção de castanha-da-amazônia. 2017 Disponível em: https:// www.embrapa.br/busca-de-noticias/-/noticia/26131296/ pesquisa-aponta-queda-de-70-na-producao-de-castanha-da-amazonia

Ewers, R. M.; Laurance, F. W; Souza Jr., C. M. Temporal fluctuations in Amazonian deforestation rates. Environmental Conservation, 35(4), 303-310, 2008. doi: 10.1017/ S0376892908005122

Fearnside, P. M. Desmatamento na Amazônia: dinâmica, impactos e controle. Acta Amazonica, 36(3), 395-400, 2006. Disponível em: https://acta.inpa.gov.br/fasciculos/36-3/ PDF/v36n3a18.pdf

Fearnside, P. Business as Usual: A Resurgence of Deforestation in the Brazilian Amazon. Yale Enviroment 360. Yale Scholl of Forestry \& Environmental Studies. 2017. Disponível em: https//e360.yale.edu/features/business-as-usual-a-resurgence-of-deforestation-in-the-brazilian-amazon

Fu, R.; Yin, L.; Li, W. et al. Increased dry-season length over southern Amazonia in recent decades and its implication for future climate projection. Proceedings of the National Academy of Sciences of the United States of America, 110(45), 18110-18115, 2013. doi: 10.1073/pnas. 1302584110

Gloor M.; Barichivich J.; Ziv G.; Brienen R.; Schöngart J.; Peylin P.; LadvocatCintraBarcante B.; Feldpausch T.; Phillips O.; Baker J. Recent Amazon climate as background for possible ongoing and future changes of Amazon humid forests. Global Biogeochemical Cycles v. 29, p. 1384-1399. 


\section{5. https://doi.org/10.1002/2014GB005080}

Gomes, C. V. A.; Perz, S. G.; Vadjunec, J. M. Convergence and Contrasts in the Adoption of Cattle Ranching: Comparisons of Smallholder Agriculturalists and Forest Extractivists in the Amazon. Journal of Latin American Geography, 11(1), p. 99-120, 2012. doi: 10.1353/lag.2012.0018

Hansen, M. C.; Potapov, P. V.; Moore, R.; Hancher, M.; Turubanova, S. A.; Tyukavina, A.; Thau, D.; Stehman, S. V.; Goetz, S. J.; Loveland, T. R.; Kommareddy, A.; Egorov, A.; Chini, L.; Justice, C. O.; Townshend, J. R. G. High-Resolution Global Maps of 21st-Century Forest Cover Change. Science, 342, 6160, 850-853, 2013. doi: 10.1126/ science. 1244693

Hoelle, J. Rainforest Cowboys: The Rise of Ranching and Cattle Culture in Western Amazonia. Universityof Texas Press. p. 231, 2015.

Inpe - Instituto Nacional de Pesquisas Espaciais. Projeto Prodes - Monitoramento da Floresta Amazônica por Satélite. 2018.Disponível em: <http://www.obt.inpe.br/prodes/ index.php>.

IPCC. Managing the risks of extreme events and disasters to advance climate change adaptation: special report of the Intergovernmental Panel on Climate Change.1. publ ed. Cambridge: Cambridge Univ. Press, 2012.

Keohane, R. O.; Victor, D. G. Cooperation and discord in global climate policy. Nature Climate Chenge, 6, 570, 2016. doi: $10.1038 /$ nclimate2937

Lewis, S. L.; Brando, P. M.; Phillips, O. L.; Heijden, G. M. F.; van der; Nepstad, D. C. The 2010 Amazon Drought. Science, 331, 6017, 554-554, 2011. doi: 10.1126/science. 1200807

Longo, M.; Keller, M.; Dos-Santos, M. N. et al. Aboveground biomass variability across intact and degraded forests in the Brazilian Amazon. Global Biogeochemical Cycles, 30(11), 2016GB005465. doi: 10.1002/2016GB005465, 2016

Lovejoy, T. E.; Nobre, C. Amazon Tipping Point. Science Advances, 4, 2018. doi: 10.1126/sciadv.aat2340

Marengo, J. A.; Espinoza, J. C. Extreme seasonal droughts and floods in Amazonia: causes, trends and impacts. Inter- national Journal of Climatology, 36, 1033-1050, 2016. doi: $10.1002 /$ joc. 4420

Mascarenhas, F. S. Dinâmica da cobertura florestal e ocorrência de incêndios florestais e suas implicações na gestão da Reserva Extrativista Chico Mendes. Manaus. x, 52 f.: il. Dissertação (Mestrado Profissional em Gestão de Áreas Protegidas) - Instituto Nacional de Pesquisas da Amazônia, INPA, Manaus, 2017.

Milodowski, D.; Mitchard, E.; Williams, M. Forest loss maps from regional satellite monitoring systematically underestimate deforestation in two rapidly changing parts of the Amazon. Environmental Research Letters, 2017. doi: 10.1088/1748-9326/aa7e1e

Munier, S.; Carrer, D.; Planque, C.; Camacho, F.; Albergel, C.; Calvet, J.C. Satellite Leaf Area Index: Global Scale Analysis of the Tendencies Per Vegetation Type Over the Last 17 Years. Remote Sensingv, 10, 2018. doi: 10.3390/ rs 10030424

Nobre, A. D. O futuro climático da Amazônia: relatório de avaliação cientifica. São José dos Campos: ARA: CCSTINPE: INPA, 2014. 42 p. Disponível em: <https://www. socioambiental.org/sites/blog.socioambiental.org/files/ futuro-climatico-da-amazonia.pdf $>$

Nepstad, D. C.; Schwartzman, S.; Bamberger, B.; Santilli, M.; Ray, D.; Schlesinger, P.; Lefebvre, P.; Alencar, A. A. C.; Prinz, E.; Fiske, G.; Rolla, A. Inhibition of Amazon Deforestation and Fire by Parks and Indigenous Lands. Conservation Biology, 20, 65-73, 2006. doi: 10.1111/j. 1523-1739.2006.00351.x

Numata, I.; Cochrane, M. A. Forest Fragmentation and Its Potential Implications in the Brazilian Amazon between 2001 and 2010. Open Journal of Forestry, 2(4), 265-271, 2012. doi: 10.4236/ojf.2012.24033

Oliveira, K. A. Dinâmica das mudanças na paisagem na reserva extrativista Chico Mendes no estado do Acre, entre 1989 a 2010. 2013. xvi, 127 f., il. Dissertação (Mestrado em Ciências Florestais) - Universidade de Brasília, Brasília, 2013.

Pfaff, A.; Robalino, J.; Lima, E.; Sandoval, C.; Herrera, L. D. Governance, Location and Avoided Deforestation from Protected Areas: Greater Restrictions Can Have Lower Im- 
pact, Due to Differences in Location. World Development, Land Tenure and Forest Carbon Management, 55, 7-20, 2014. doi: 10.1016/j.worlddev.2013.01.011

Phillips O. L.; van der Heijden G.; Lewis S. L.; López-González G.; Aragão L. E. O. C.; Lloyd J. et al. Drought-mortality relationships for tropical forests. New Phytologist, 187, 631-646, 2010. doi: 10.1111/j.1469-8137.2010.03359.x

Phillips, O. L.; Brienen, R. J. W. Carbon uptake by mature Amazon forests has mitigated Amazon nations' carbon emissions. Carbon Balance and Management, 12(1), 2017. doi: 10.1186/s132021-016-0069-2

Richards, P.; Arima, E.; Vanwey, L.; Cohn, A.; Bhattarai, N. Are Brazil's Deforesters Avoiding Detection? Conservation Letters, 10, 470-476, 2017. doi: 10.1111/conl.12310

Silva, S. S.; Fearnside, F. M.; Graça, P. M. L. A.; Brown, I. F.; Alencar, A.; Melo, A. F. Dynamics of forest fires in the southwestern Amazon. Forest Ecology and Management, 424, 312-322, 2018. doi: 10.1016/j.foreco.2018.04.041

Soares-Filho, B.; Nepstad, D.; Curran, L.; Cerqueira, G. C.; Garcia, R. A.; Ramos, C. A.; Voll, E.; McDonald, A.; Lefebvre, P.; Schlesinger, P.; McGrath, D. Cenários de desmatamento para a Amazônia. Estudos Avançados, 19(54), 137-152, 2005. doi: 10.1590/S0103-40142005000200008

Soares-Filho, B.; Moutinho, P.; Nepstad, D.; Anderson, A.; Rodrigues, H.; Garcia, R.; Dietzsch, L.; Merry, F.; Bowman, M.; Hissa, L.; Silvestrini, R.; Maretti, C. Role of Brazilian Amazon Protected Areas in Climate Change Mitigation. Proceedings of the National Academy of Sciences, 107(24), 10821-10826, 2010. doi: 10.1073/pnas.0913048107

Tyukavina, A.; Hansen, M. C.; Potapov, P. V.; Stehman, S. V.; Smith-Rodriguez, K.; Okpa, C.; Aguilar, R. Types and rates of forest disturbance in Brazilian Legal Amazon, 2000-2013. Science Advances, 3, 2017. doi: 10.1126/ sciadv. 1601047

Vanwey, L. K.; Ostrom, L.; Meretsky, V. Teorias subjacentes ao estudo de interações homem-ambiente. In: Ostrom, E.; Moran, E. F. (Org.). Ecossistemas florestais: interação homem-ambiente. São Paulo: Editora Senac, 2009.

Vitel, C. S. M. N.; Carrero, G. C.; Cenamo, M. C.; Leroy, M.; Graça, P. M. L. de A.; Fearnside, P. M. Land-Use Change
Modeling in a Brazilian Indigenous Reserve: Construction of a Reference Scenario for the Suruí REDD Project. Human Ecology, 41(6), 807-826, 2013. doi: 10.1007/s10745-0139613-9

Yanai, A. M.; Fearnside, P. M.; Graça, P. M. L. de A.; Nogueira, E. M. Avoided deforestation in Brazilian Amazonia: simulating the effect of the Juma Sustainable Development Reserve. Forest Ecology and Management, 282, 78-91, 2012. doi: 10.1016/j.foreco.2012.06.029

Zambrano, A. M. A. et al. Deforestation Drivers in Southwest Amazonia: Comparing Smallholder Farmers in Iñapari, Peru, and Assis Brasil, Brazil. Conservation and Society, 8(3), 157-170, 2010. doi: 10.4103/0972-4923.73805

Zhu, Z.; Piao, S.; Myneni, R. B.; Huang, M.; Zeng, Z.; Canadell, J. G.; Ciais, P.; Sitch, S.; Friedlingstein, P.; Arneth, A.; Cao, C.; Cheng, L.; Kato, E.; Koven, C.; Li, Y.; Lian, X.; Liu, Y.; Liu, R.; Mao, J.; Pan, Y.; Peng, S.; Peñuelas, J.; Poulter, B.; Pugh, T. A. M.; Stocker, B. D.; Viovy, N.; Wang, X.; Wang, Y.; Xiao, Z.; Yang, H.; Zaehle, S.; Zeng, N. Greening of the Earth and its drivers. Nature Climate Change, 6, 791, 2016. doi: 10.1038/nclimate3004 
Apêndice A - Seringais da Reserva Extrativista Chico Mendes e as suas áreas de abrangência em ordem alfabética.

\begin{tabular}{|c|c|c|c|}
\hline Seringal & Área (ha) & Seringal & Área (ha) \\
\hline Albracia & 24.906 & Paraguaçú & 16.864 \\
\hline Amapá & 53.278 & Petrópolis & 18.654 \\
\hline Apodi & 18.700 & Pinda & 12.841 \\
\hline Arari & 10.438 & Porongaba & 9.370 \\
\hline Barra & 21.988 & Porvir & 10.672 \\
\hline Boa Vista & 34.267 & Riozinho & 12.762 \\
\hline Bom Fim $\backslash$ Remanso & 36.019 & Rubicon & 2.917 \\
\hline Canamari & 8.391 & Sai Cinza & 6.695 \\
\hline Curitiba & 12.242 & Santa Fé & 1.974 \\
\hline Dois Irmãos & 8.206 & São Cristovão & 27.922 \\
\hline Etelvi & 9.303 & São Francisco & 32.555 \\
\hline Filipinas & 33.755 & São Francisco do Iracema & 45.653 \\
\hline Floresta & 12.875 & São João do Iracema & 3.990 \\
\hline Fronteira & 35.290 & São José & 8.796 \\
\hline Guanabara & 66.803 & São Pedro & 13.924 \\
\hline Humaitá & 8.248 & São Salvador & 2.569 \\
\hline Icuriã & 67.378 & Siberia & 14.870 \\
\hline Independência & 13.264 & Tabatinga & 86.234 \\
\hline Nazaré & 33.880 & Triunfo & 9.785 \\
\hline Nova Esperança & 8.040 & Tupá & 2.283 \\
\hline Nova Olinda & 34.929 & Vale que Tem & 3.123 \\
\hline Pacuara & 5.734 & Venezuela & 12.552 \\
\hline Palmari & 8.740 & Vila Nova & 29.004 \\
\hline
\end{tabular}


Apêndice B - Desmatamento nos seringais da Reserva Extrativista Chico Mendes, medido pelo Prodes, 1988 a 2014.

\begin{tabular}{|c|c|c|c|c|c|c|c|}
\hline Soring & $\begin{array}{c}\text { Desmatamento } \\
\text { (ha) }\end{array}$ & $\begin{array}{c}\text { Desmatamento } \\
\text { (ha) }\end{array}$ & $\begin{array}{c}\text { Desmatamento } \\
\text { (ha) }\end{array}$ & $\begin{array}{c}\% \text { de } \\
\text { Desmate }\end{array}$ & Polígonos & Polígonos & Total \\
\hline Netimgal & Até o ano 2000 & De 2001 a 2014 & $\begin{array}{c}\text { Acumulado até } \\
2014\end{array}$ & da RECM & $\begin{array}{c}\text { Até o ano } \\
2000\end{array}$ & $\begin{array}{c}\text { De } 2001 \\
\text { a } 2014\end{array}$ & Polígonos \\
\hline Nova Esperança & 1.882 & 2.265 & 4.148 & 7 & 183 & 488 & 671 \\
\hline Venezuela & 2.383 & 518 & 2.900 & 5 & 88 & 117 & 205 \\
\hline São Francisco & 877 & 2.020 & 2.898 & 5 & 129 & 406 & 535 \\
\hline Icuriã & 1.394 & 1.448 & 2.842 & 5 & 200 & 412 & 612 \\
\hline Filipinas & 1.416 & 1.239 & 2.655 & 5 & 256 & 351 & 607 \\
\hline São Cristovão & 1.633 & 964 & 2.597 & 5 & 252 & 332 & 584 \\
\hline Guanabara & 955 & 1.630 & 2.585 & 5 & 162 & 388 & 550 \\
\hline Vila Nova & 1.705 & 652 & 2.357 & 4 & 141 & 192 & 333 \\
\hline Paraguaçú & 712 & 1.394 & 2.106 & 4 & 123 & 354 & 477 \\
\hline Porvir & 1.395 & 695 & 2.090 & 4 & 103 & 180 & 283 \\
\hline Amapá & 975 & 805 & 1.779 & 3 & 140 & 205 & 345 \\
\hline Tabatinga & 717 & 755 & 1.472 & 3 & 102 & 185 & 287 \\
\hline Independência & 991 & 407 & 1.398 & 2 & 66 & 68 & 134 \\
\hline $\begin{array}{l}\text { São Francisco } \\
\text { do Iracema }\end{array}$ & 539 & 820 & 1.360 & 2 & 125 & 181 & 306 \\
\hline Nazaré & 865 & 492 & 1.357 & 2 & 160 & 158 & 318 \\
\hline Porongaba & 724 & 569 & 1.293 & 2 & 103 & 160 & 263 \\
\hline Rubicon & 852 & 381 & 1.232 & 2 & 42 & 87 & 129 \\
\hline
\end{tabular}




\begin{tabular}{|c|c|c|c|c|c|c|c|}
\hline Triunfo & 536 & 664 & 1.200 & 2 & 87 & 141 & 228 \\
\hline Etelvi & 433 & 731 & 1.164 & 2 & 45 & 189 & 234 \\
\hline Apodi & 414 & 743 & 1.157 & 2 & 65 & 176 & 241 \\
\hline $\begin{array}{l}\text { Bom Fim } \backslash \\
\text { Remanso }\end{array}$ & 338 & 782 & 1.120 & 2 & 42 & 159 & 201 \\
\hline Floresta & 665 & 447 & 1.111 & 2 & 120 & 133 & 253 \\
\hline Humaitá & 626 & 481 & 1.108 & 2 & 88 & 154 & 242 \\
\hline Santa Fé & 314 & 771 & 1.085 & 2 & 28 & 128 & 156 \\
\hline Boa Vista & 607 & 458 & 1.065 & 2 & 158 & 168 & 326 \\
\hline Petrópolis & 889 & 146 & 1.035 & 2 & 16 & 38 & 54 \\
\hline Pinda & 486 & 438 & 924 & 2 & 75 & 128 & 203 \\
\hline Albracia & 330 & 334 & 664 & 1 & 86 & 92 & 178 \\
\hline Riozinho & 304 & 346 & 650 & 1 & 78 & 109 & 187 \\
\hline Palmari & 384 & 263 & 647 & 1 & 85 & 70 & 155 \\
\hline Siberia & 333 & 299 & 632 & 1 & 76 & 80 & 156 \\
\hline Fronteira & 413 & 154 & 566 & 1 & 50 & 47 & 97 \\
\hline São José & 433 & 120 & 552 & 1 & 55 & 42 & 97 \\
\hline Pacuara & 169 & 345 & 515 & 1 & 22 & 81 & 103 \\
\hline São Pedro & 323 & 167 & 490 & 1 & 63 & 44 & 107 \\
\hline Sai Cinza & 185 & 290 & 474 & 1 & 25 & 66 & 91 \\
\hline Dois Irmãos & 318 & 127 & 445 & 1 & 79 & 55 & 134 \\
\hline
\end{tabular}




\begin{tabular}{|c|c|c|c|c|c|c|c|}
\hline Nova Olinda & 172 & 248 & 420 & 1 & 43 & 62 & 105 \\
\hline Canamari & 186 & 208 & 394 & 1 & 24 & 49 & 73 \\
\hline Vale que Tem & 239 & 146 & 385 & 1 & 22 & 30 & 52 \\
\hline Barra & 194 & 141 & 336 & 1 & 37 & 41 & 78 \\
\hline São Salvador & 124 & 199 & 323 & 1 & 22 & 46 & 68 \\
\hline $\begin{array}{l}\text { São João do } \\
\text { Iracema }\end{array}$ & 150 & 116 & 266 & 0 & 24 & 14 & 38 \\
\hline Tupá & 77 & 48 & 125 & 0 & 13 & 11 & 24 \\
\hline Arari & - & 18 & 18 & 0 & - & 6 & 6 \\
\hline Curitiba & - & 7 & 7 & 0 & - & 3 & 3 \\
\hline
\end{tabular}


Apêndice C - Áreas de regeneração florestal nos seringais da Reserva Extrativista Chico Mendes medidas pelo método Hansen (GFC), 2000 a 2012.

\begin{tabular}{|c|c|c|c|c|}
\hline Seringal & Desmatamento (ha) & Area Regenerada & Poligonos & Regeneração (\%) \\
\hline São João & 46 & 32 & 140 & 70 \\
\hline Independência & 255 & 147 & 500 & 58 \\
\hline Dois Irmãos & 118 & 47 & 196 & 40 \\
\hline Petrópolis & 149 & 52 & 132 & 35 \\
\hline Tupá & 21 & 7 & 50 & 34 \\
\hline Floresta & 270 & 91 & 430 & 34 \\
\hline Albracia & 204 & 67 & 304 & 33 \\
\hline Siberia & 253 & 80 & 318 & 32 \\
\hline Palmari & 190 & 51 & 246 & 27 \\
\hline São Pedro & 173 & 46 & 226 & 27 \\
\hline Barra & 152 & 37 & 162 & 24 \\
\hline Nazaré & 421 & 98 & 534 & 23 \\
\hline Fronteira & 151 & 32 & 150 & 21 \\
\hline Boa Vista & 519 & 95 & 520 & 18 \\
\hline Venezuela & 302 & 51 & 280 & 17 \\
\hline Paraguaçú & 1.008 & 171 & 796 & 17 \\
\hline Vila Nova & 645 & 105 & 520 & 16 \\
\hline
\end{tabular}




\begin{tabular}{|c|c|c|c|c|}
\hline Icuriã & 1.460 & 232 & 1.144 & 16 \\
\hline São Cristovão & 1.154 & 142 & 818 & 12 \\
\hline Humaitá & 478 & 58 & 290 & 12 \\
\hline Amapá & 1.069 & 125 & 602 & 12 \\
\hline Canamari & 184 & 20 & 84 & 11 \\
\hline São José & 173 & 18 & 120 & 10 \\
\hline São Francisco & 1.584 & 161 & 828 & 10 \\
\hline Porvir & 874 & 88 & 434 & 10 \\
\hline $\begin{array}{l}\text { São Francisco do } \\
\text { Iracema }\end{array}$ & 737 & 71 & 388 & 10 \\
\hline Filipinas & 1.436 & 117 & 568 & 8 \\
\hline Tabatinga/Santa Ana & 844 & 66 & 306 & 8 \\
\hline Porongaba & 641 & 46 & 270 & 7 \\
\hline Guanabara & 2.002 & 142 & 616 & 7 \\
\hline Riozinho & 456 & 32 & 140 & 7 \\
\hline Pinda & 608 & 36 & 172 & 6 \\
\hline Bom Fim & 697 & 34 & 222 & 5 \\
\hline Pacuara & 289 & 14 & 80 & 5 \\
\hline Apodi & 814 & 36 & 198 & 4 \\
\hline
\end{tabular}




\begin{tabular}{|c|c|c|c|c|}
\hline Etelvi & 792 & 31 & 156 & 4 \\
\hline Rubicon & 439 & 16 & 94 & 4 \\
\hline Triunfo & 766 & 21 & 144 & 3 \\
\hline Curitiba & 21 & 0 & 6 & 2 \\
\hline Nova Esperança & 3.269 & 60 & 372 & 2 \\
\hline Vale que Tem & 134 & 2 & 18 & 2 \\
\hline Arari & 11 & 0 & 2 & 1 \\
\hline Nova Olinda & 441 & 6 & 48 & 1 \\
\hline Sai Cinza & 352 & 4 & 34 & 1 \\
\hline Santa Fé & 1.192 & 8 & 48 & 1 \\
\hline São Salvador & 169 & 1 & 10 & 1 \\
\hline $\begin{array}{l}\text { Resex Chico } \\
\text { Mendes }\end{array}$ & 27.961 & 2.796 & 13.716 & 10 \\
\hline
\end{tabular}

